\title{
The Pragmatics of Hoax Email Business Proposals
}

\author{
Innocent Chiluwa (Ota, Nigeria)
}

\begin{abstract}
This study applies the speech acts theory to the study of discourse strategies and functions of hoax email business proposals otherwise known as "419 emails" - '419' being the Nigerian term for all forms of online/financial fraud. The hoax mails are in form of email 'business proposals' involving money transfers/claims of dormant bank accounts overseas. Five types are identified namely: (i) money transfers, (ii) next-of-kin claims, (iii) fortune bequeathing, (iv) charity donations and (v) investment opportunities. Data comprises 52 email samples collected from the researcher's inboxes, colleagues and students' email inboxes between January, 2008 and March, 2009 in Ota, Nigeria. The study reveals that the business proposals perform speech acts such as expressive, representative, commissive and directive acts; the most frequently used being representative as the proposals are structured as narratives. The expressive act is used in form of greetings and polite address forms in order to win the interest of the receiver. The commissive act is used as a persuasive strategy while making unrealistic and suspicious promises to the receiver, while the directive act is used to urge the receiver to act promptly. The study also shows that this genre of Computer-mediated communication (CMC) has become a regular part of our internet social life, and is not likely to be extinct in the near future as previous studies of email hoaxes have predicted, since economic hardship being witnessed by the world today can force people to criminal activities.
\end{abstract}

\section{$1 \quad$ Introduction}

The increasing usability of the internet for sending messages while the sender remains anonymous and the rise of computer literacy and in fact the control of advanced internet skills by so many people across the globe have simplified and fully incorporated online communication into global communication practice (Blommaert 2005). However, there is an increasing application of internet resources especially the electronic mail (email) to the practise of digital deceptions/online financial scams. All forms of frauds on the internet begin from the point of using language in a particular way, to entertain, persuade and eventually convince. This study examines some pragmatic strategies that have been applied by the writers of hoax email business proposals, which have often resulted in big-time online scams.

"Hoax email business proposals" refers to unsolicited scam emails, usually sent to receivers' inboxes, or as spam mails. In Nigeria they are known as '419' mails and referred to as "Nigeria mail" (Heyd 2008) in some quarters. It is not certain however that all fraud-oriented mails are exclusively written by Nigerians. The geographical base of the writers presented in the information headers of the mails is generally uncertain. According to Blommaert (2005: 2) the mails originate from "somewhere in the periphery of the world and sent to a large number of addressees in the core countries of the world system". Our data show that hoax mails are assumed to originate from 17 countries representing African, Asia/Middle East, Australia, Europe and North America. Five types of the hoax/scam business proposals are to be 
examined in this study namely (i) money transfers (MT), (ii) next-of-kin claims (NKC), (iii) fortune bequeathing (FB), (iv) charity donations (CD) and (v) investment opportunity (IO).

The first type is when the receiver is asked to make his bank account available for a transfer of millions of dollars in a dormant foreign account after which the receiver gets between $35 \%$ and $40 \%$ of the total sum. Sometimes the money is not in a bank but was recovered from a hidden safe, somewhere (e.g. in Iraq) and needs to be transferred to the receiver's accounts for 'safe keeping'. The second proposal is when the receiver is told to act as a next-of-kin for someone, otherwise known as 'a client' who presumably dumped some millions of dollars in the "African Development Bank, or 'Bank of Africa', in Ouagadougou, Burkina Faso". The client had died in a plane crash with his entire family and the Bank, realizing that the dead businessman leaves no relatives, is asking the receiver to act as the next-of-kin, claim the money and share it with the writer of the proposal. The third type which I termed 'fortune bequeathing' is when the receiver is told that a multi-millionaire had died in a foreign country, and had left for the receiver all his wealth, worth millions of US dollars in a foreign bank; the bank suddenly discovers the receiver's name as the beneficiary of the abandoned money. The fourth is when 'a sister in Christ', whose husband has died leaving her his fortune, who at the point of writing the email had been diagnosed with an obnoxious cancer. Since she was expected to die in a couple of months, now needs a 'born again' individual who would use her money for charity and to fund churches. The fifth type of the hoax mails is asking the receiver to help receive a safe containing millions of US dollars from a security company on behalf of a youth whose father has died. The receiver is to identify an investment opportunity in his country where the money could be invested. The investor is expected to get about $10 \%$ of the profit in return. Others in this category also involve the transfer of huge sums of money into the receiver's account for investment purpose.

For any of these 'business' proposals, the receiver is required to send his name, home address, phone numbers and other relevant personal information to the writer of the hoax email in order to facilitate a speedy execution of the business. This study applies the speech act theory to analyse:

(i) The forms and structures of the hoax emails in the data

(ii) Pragmatic strategies in the openings and closings

(iii) How the contents of the proposals perform speech acts at every level of persuasions

This approach examines persuasive strategies applied by the deceptive email writers and the kind of effects they have had in the past; why they have constantly existed despite the fact that people are aware of the insincerity and unreliability of spam emails. This study also attempts to explain the reason for the spread and proliferation of this kind of email messages in recent times.

\section{Review of Literature}

Since email has become a tool of mass global communication with the advantages of simplicity, and flexibility (Lan 2001), users exploit the medium for both personal and business related communications. Studies reveal that both personal and workplace emails perform significant functions and roles, including social, cultural and economic (Yates 1996; Collot/Belmore 1996; Skovholt/Svennevig 2006). At the workplace, email communication increases access to new people, breaks spatial barriers, and provides access to information that otherwise wouldn't have been accessible (Garton/Wellman 1995). Managers for instance, have been able to control their subordinates from distances (Brigham/Corbett 1997). In organisations where employers have access to their employees' email accounts, monitoring 
and control of the on-going working process have also been possible (Skovholt/Svennevig 2006).

Literature on the study of email as a medium for disseminating digital deceptions and online clams are very lean, showing that much have yet to be done by scholars in CMC research. Among the first studies on 'email hoaxes' are Fernback (2003), Blommaert (2005) and Heyd (2008); Fernback's is a textual study of spurious e-mail virus warnings. Heyd (2008) is an extensive genre study of email hoaxes, mainly fake virus warnings, 'giveaway hoaxes', charity hoaxes, urban legends and 'hoaxed hoaxes'. The study includes a description of forms, discourse structures and pragmatic analyses of 'digital lies'. (Kibby 2005) deals with textual analyses of forwarded and unsolicited mails, while Barron (2006) takes a macro-textual approach in the study of spam emails from medical supplies. Other studies on web hoaxes and counterfeit sites (Mintz 2002) and 'junk mails' (Orasan/Krishnamurty 2002) have also been concerned mainly with the textual features and the unreliability of this kind of digital communication.

One of the very first studies of '419' mails, which is closely related to the present study is Blommaert (2005). The study takes a sociolinguistic approach which also examines the 'grassroot' level of English of the writers which ironically does not match their advanced digital literacy. Blommaert however suggests that the linguistic, stylistic and generic features of such texts should be studied. The current study applies a discourse approach to the investigation of pragmatic strategies in the hoax mails that are responsive for their persuasive influences.

\section{Theoretical Considerations}

Despite the controversies that have trailed Austin's speech (1962, also Searle 1969), the primary contribution of this theory is that language is to be recognised as a tool for performing actions. Therefore the meaning we associate with an utterance merely represents the intention the user has for making the utterance, or the effects such utterances are intended to have on the mind of the hearer. This implies that rather than talk of linguistic forms of the utterance, we talk of the functions of the forms. Austin postulates that every utterance performs (i) the Locutionary act, which is the act that utters a sentence with a certain meaning using the grammar, phonology and semantics of the language, (ii) the Illocutionary act, which is the intention of an utterance to constitute either an act of promise, command, criticism, agreement, greeting, pronouncement etc., (iii) the Perlocutionary act, which is the effect or the response it achieves on the hearer like embarrassment, fear, confusion, enjoyment, or amusement. If any sentence is taken as an utterance, it has a force, and it doesn't matter if the sentence is true or false; rather the utterance represents the intention the speaker has for making an utterance. The illocutionary act is therefore where speakers actually "do things with words". According to Austin, illocutionary act is performed by 'performative sentences', because by virtue of its structure, a performative sentence has a 'conversational force' like pronouncing a man and a woman husband and wife or sentencing a defendant in court. The illocutionary act carried out by the use of some sentence is to invest the utterance of that sentence with a particular illocutionary force.

Searle (1969) gives the 'felicity conditions' for performing speech acts, which determine when the performance of an act may be appropriate or inappropriate. He further gives what may be considered as an extension of Austin's illocutionary acts. Searle (1975) gives 5 types of acts that are performed in speaking as follows:

(i) Representative Act - describing events, process, states; also assertions, claims, reports, suggestion etc. 
(ii) Declarative Act-pronouncing, sentencing, christening etc.

(iii) Directive Acts - commanding, requesting, pleading, inviting etc.

(iv) Expressive Acts - greeting, scolding, condoling, appreciating, congratulating, apologizing etc.

(v) Commissive Acts - betting, challenging, promising, threatening, offering, vowing, warning etc.

It must be pointed out that either of these acts may be performed in written texts. The current study views text-based (email) computer-mediated communication as potential data for the study of speech acts. The analyses show how the various communicative/persuasive strategies in the emails actually perform most or all of the above speech acts, representing the functions of the proposals or the writers' intentions.

\section{Data/Method}

The corpus comprises fifty-two (52) individual email samples, collected from (i) researcher's own email box (ii) researcher's friend's/colleague's mailbox (iii) researcher's student's email accounts. The difficulty with the collection of data of this nature is that most people that receive '419' mails quickly delete them. In fact many who receive spam mails hardly open them for fear of viruses, so it was very difficult to assemble so many of such mails. Those that made theirs available were told in advance not to delete them because the researcher intended to use them for a study. The data were assembled between the early part of 2008 and early part of 2009 in Lagos and Ota regions of Nigeria.

Data are divided into the five types of hoax email business proposals identified above, namely (i) money transfers (MT) (ii) next of kin claims (NKC) (iii) fortune bequeathing (FB) (iv) charity donations (CD) and (v) investment opportunity (IO). Sub-types of these broad headings will also be examined. The distribution of the above emails in the data is shown in Table1 below.

\begin{tabular}{|l|l|l|l|l|l|}
\hline MT & NKC & FB & CD & IO & Total \\
\hline 8 & 28 & 7 & 4 & 5 & 52 \\
\hline
\end{tabular}

Table 1: Distribution of email categories in the data

As already pointed out in the introduction, analysis of data is qualitative, focusing on the forms and discourse structures of the hoax emails in the data, pragmatic strategies in the openings and closings and how the narrative contents of the emails perform speech acts.

\section{$5 \quad$ Analysis/Findings}

\subsection{Forms/discourse structure}

According to Blommaert (2005) the authors of these emails are well aware of the connections between particular styles and the shapes of utterances and particular indexicalities. So they endeavour to keep within the discourse tradition of the existing genre in order to appear real and eventually convince unsuspecting victims. Since they are to be considered as 'business letters' some of the mails are written in technical business English. As a form of business discourse the mails are structured as narratives having three segments, namely (i) the subject header, (ii) the message and (iii) the closing. The header contains information about the writer's organization and his designation.

The closing includes the sign-off and the sign-off usually includes the name of the writer. 
All five categories with their sub-types are constructed as narratives in the following order:

I Opening/greeting

II Introduction (including the identity of the writer and often an apology for making contact without prior notice)

III A narrative, which includes a description of (i) the origin of the money deposited in a foreign account which the addressee is made a beneficiary; (ii) a painful experience of the death of a spouse and the money he kept in dormant account abroad to be used for charity or for raising his kids; (iii) a story of a wealthy client who deposited some millions of dollars in a foreign account and had died, leaving the money for the addressee or (iv) an investment opportunity abroad worth millions of dollars or pound sterling etc.

IV An invitation to the receiver to be engaged in the business with an offer of a profit sharing formula

$\mathrm{V}$ Request for confidentiality or an invitation to the addressee to indicate interest

VI Closing (including a request to the receiver to reply immediately)

Because of their narrative structure, the mails are usually long, often taking a whole page of an A4 paper. Some short ones take half a page. A sample of one of each of the categories is reproduced in the course of the analysis as we examine the discourse/pragmatic strategies in the categories.

\subsection{Pragmatic Strategies}

\subsubsection{Opening Formula/Greetings}

Greeting as a form of social communication generally features in both spoken and written discourses and functions as a polite means of creating a comfortable atmosphere for social interaction. As it is also expected in business contexts, most business letters contain formal openings as a form of politeness strategy. In most societies, greeting forms part of positive politeness that enhances social relationship and solidarity, smooth communication, and a favourable outcome for the message (Ide 1989; Agyekum 2008). In all the various types of hoax email proposals under study, greeting is used as a form of opening. Interestingly however, formal openings such as "dear sir" or "dear sir/madam", are not commonly used. Most of the mails though formal in content carry informal opening/greeting forms. Table 2 below gives a general overview of the opening formulas in the data.

\begin{tabular}{|lrr|}
\hline Opening/Greeting Formula & no. & $\%$ \\
\hline Dear friend & 16 & 30.7 \\
Good day & 4 & 7.7 \\
Hello & 3 & 5.7 \\
Dear Sir/Madam & 3 & 5.7 \\
Dearest in Christ & 3 & 5.7 \\
Hello friend & 2 & 3.8 \\
Hello, hope you're ok & 2 & 3.8 \\
Dear Sir & 2 & 3.8 \\
Greetings & 2 & 3.8 \\
Happy New Year & 2 & 3.8 \\
Sir/Madam & 1 & 1.9 \\
Attention & 1 & 1.9 \\
Attention friend & 1 & 1.9 \\
\hline
\end{tabular}




\begin{tabular}{|lrr|}
\hline Attention dear & 1 & 1.9 \\
Attention beneficiary & 1 & 1.9 \\
Attention fund beneficiary & 1 & 1.9 \\
Dear beloved one & 1 & 1.9 \\
Dearest one & 1 & 1.9 \\
Dearest in the Lord & 1 & 1.9 \\
Good day to you & 1 & 1.9 \\
Compliments of the Season & 1 & 1.9 \\
With due respect & 1 & 1.9 \\
Asalam-Alaikom & 1 & 1.9 \\
\hline & 52 & 99.2 \\
\hline
\end{tabular}

Table 2: Distribution of Opening/Greeting formula in the data

Only $11.5 \%$ of the data is introduced formally with opening such as "dear sir", "dear sir/madam", and "sir/madam". The remaining $88.5 \%$ contain informal opening/greeting forms with some starting off with social and religious undertones, reflecting linguistic politeness. According to Frazer (1990) politeness is a social norm, a conversational maxim, a face-saving tact and a conversational-contract views. Therefore politeness in discourse is virtually the same as using language appropriately (Agyekum 2008). All the above greetings perform the expressive acts proposed by Searle (1969). This act, i.e. greeting, appreciating, congratulating etc, enables the writers appear sociable. By applying informal/religious forms of address and greeting like "dear friend", "dear beloved one", "dearest in Christ", "asalam-alaikom", etc., they seek a subtle discursive inroad to the receiver's mind. This discourse function is to trigger the emotion of the reader, since it is expected that anyone addressed with this kind of emotional appeal would want to listen or read what the speaker/writer has to say. Significantly, this manner of address exploits some religious sentiments and by greeting the religious way, the writer identifies with Christianity or Islam and in turn defines his own social identity, (Chiluwa, 2008c); this is often very powerful in today's social communication. Most people are familiar with notorious online financial scams going on so they are often apprehensive when they receive unsolicited 'business proposals'. This form of discourse/expressive strategy suggests that the writers are aware that people are not likely to subscribe to their proposals, so they pretend to appear real and acceptable.

\subsubsection{Introduction/Discourse Initiation}

The next stage of discourse initiation besides greeting is a short formal introduction sometimes in form of an apology for initiating discourse. In the five (5) representative samples for each of the groups, there is a short prelude to self identification as part of the introduction. Examples are given below:

(a) This message might meet you in utmost surprise however, it's just my urgent need for a foreign partner that made me contact you for this transaction (NKC)

(b) With Due Respect and Humanity, I was compelled to write to you under a humanitarian ground $(\mathrm{CD})$

(c) First of all, let me introduce myself to you (FBI)

(d) With a very desperate need for assistance, I have surmond up courage to contact you (MT)

(e) Actually I did not want to discuss this matter with you before but after fasting and prayer I just decided to contact you for your help, please I real need your help (IO) 
While most of the introductions perform the representative acts of stating, asserting and introducing, some are directive i.e, requesting and inviting. In the African context, like in many other cultures, it is often required that interactants begin the actual message with a brief introduction. Adegbija (1995), describes this as "atmosphere sanitizing" tact, thus preparing the ground for a successful interaction. It is generally considered impolite to initiate a conversation without this prelude especially if a hearer lacks prior knowledge of the subject matter. So the writers of the hoax business proposals apply this strategy even before introducing themselves. In some of the mails in the data, the writers appeal to the receiver for pardon for intruding into their privacy, or for choosing that medium for communicating such serious/sensitive business.

The IO above appeals to religious sensibility of the receiver, tactically appealing to the addressee's commitment to Christian practice. The receiver is to view the deceptive mail as a product of 'fasting and praying' and therefore deserves prompt action. The 419ers understand the very strong influence of religion in today's world, so they come in the name of God to deceive people.

Self identification as part of the introduction is a strategy that requires that the writer state his/her name and contact address. In the representative data above and in $95 \%$ of the entire corpus the names and assumed business affiliations of the writers are clearly stated. Hence:

(a) I am the manager of auditing and accounting department of AFRICA BANK (AB) here in Ouagadougou Burkina Faso (name omitted). (NKC)

(b) My name is Rebecca Williams. I was born in Baltimore, Maryland; I am married to Mr. Jeff WILLIAMS director J.C Industries Cote d'Ivoire. We were married for 36 years without a child. He died after a Cardiac Arteries Operation. And Recently, My Doctor told me that I would not last for the next six months due to my cancer problem (cancer of the lever and stroke). (CD)

(c) I am Dr. Williams Smith, the personal assistant to the Governor of the Central Bank of Nigeria, Prof. Chukwuma C. Soludo. I am a man of conscience who has the fear of God and human sympathy. (BFI)

(d) My name is Sgt Henshaw Wear. I am an American soldier with Swiss background, serving in the military with the army's 3rd infantry division. (MT)

(e) I am 20 years old Girl. I leave with younger brother and we leave alone because we don't want the people who killed my late Father, to kill us too. I will be very happy if you promised me that you will keep this secret until this money arrival your care in your country. (IO)

Again the introductions are stating and asserting the business and social identity of the writers, hence performing the representative act. The function of this act as expected in any business-oriented letter is to establish the business and legal identities of the writers in order to satisfy the legal requirements for running a business. However, a sudden contact with an unknown addressee is usually suspicious until a clear and elaborate introduction is done. The writers are aware of this, so they endeavor to claim high professional/administrative positions often addressing themselves as "Dr." or "barrister", in order to appear responsible and respected. The writer of BFI, ironically describes himself as "a man of conscience who has the fear of God and human sympathy", unwittingly leaving his next statement highly suggestive. So the self-identifying strategy not only identifies the writer but gives the proposal an assumed sort of credibility. 


\subsubsection{Narrativity}

According to Heyd (2008), narrativity is an elementary and important quality of human discourse, which is not limited to fictional prose. In pragmatic theory, every sentence/utterance is by implication a speech act, and it is quite easy to see how the writers of the hoax business proposal perform representative acts while narrating long stretches of events. It also shows how narrative discourse incorporates pragmatic tact, either as performing actions, complying with or violating 'cooperative principles', (Grice 1975) or deploying other forms of discourse strategies.

Examples below are from the data samples:

\section{NKC}

In my department I discovered an abandoned sum of US $\$ 10.5 \mathrm{~m}$ dollars Ten Million Five Hundred US dollars) in an account that belongs to one of our foreign customer GEORGE BRUMLEY that who died in a plane crash in Kenya 2003.You can confirm the genuiness of the deceased death by clicking on the website below http://www.cnn.com/2003/WORLD/africa/ 07/20/kenya.crash/index.html

Since we got information about his death, we have been expecting his next of kin to come over and claim his money because we can not release it unless some body applies for it as next of kin or relation to the deceased as indicated in our banking guidlings and laws but unfortunately we learnt that all his supposed next of kin or relation died alongside with him at the plane crash leaving nobody behind for the claim. It is therefore upon this discovery that I now decided to make this business proposal to you, so that the money can be release to you as the next of kin or relation to the deceased for safety and subsequent disbursement since nobody will come for it and we don't want this money to go into the bank treasury as unclaimed dormant fund. The banking law and guidline here stipulates that if such money remained unclaimed after TEN YEARS the money will be transfered into the bank treasury as unclaimed dormant fund. The request of foreigner as next of kin in this business is occassioned by the fact that the customer was a foreigner and a Burkinabe like me can not stand as next of kin to a foreigner.

\section{$\mathrm{CD}$}

Before my husband died last year there is this sum $\$ 2.8$ Million Dollars that he deposited with a Private Finance Company here In Ivory Coast. Presently this money is still in the Vault of the Company. Having known my condition I decided to donate this fund to any good God fearing brother or sister that will utilize this fund the way I am going to instruct herein.

I want somebody that will use this fund according to the desire of my late husband to help Less privileged people, orphanages, widows and propagating the word of God. I took this decision because I don't have any child that will inherit this fund, And I don't want in away where this money will be used in an ungodly way. This is why I am taking this decision to hand you over this Fund. I am not afraid of death hence I know where I am going. I want you to always remember me in your daily prayers because of my up coming Cancer Surgery.

\section{FBI}

For some years now, your funds that is supposed to be transferred into your account as a foreign contractor or next of kin who is entitled to inherit the deceased money has been delayed base on series of unnecessary reasons. The funds have not yet been transferred into your account, while you have been suffering and spending a lot of money on documents also paid a lot of charges which is demanded from the people who is helping you to get this funds transferred into your account but all their efforts has not yielded any fruit. The truth of the matter is that my boss, Prof. Chukwuma C. Soludo, the Governor of the CBN and some Government officials deliberately did not allow the money to be transferred into your account. Maybe for his selfish 
interest or he wants the money to yield much interest and he will use of the interest and get the total sum released to you after he has made a lot of profit.

That has been the system here in Nigeria and it will last for years. Our old president has left because he had been an obstacle but we thank God that we have a new president now and all problems are solved. This morning, our new president sends us a written note that all outstanding funds had to be released to the owners with immediate effect. Call me immediately. You are a lucky person because on 12th, we have settled with the United States Monetary Fund Agent also Europe and you will receive your fund in a very wonderful way. My boss is on leave which started Friday officially and it will take him one month to resume back to office and I am the person in charge of any transfer and all the signatories that will be endorsed before approval of any fund is transferred out of the country.

\section{MT}

I found your contact particulars in an address journal hence I am seeking your kind assistance to move the sum of ( $\$ 15.3$ million us. dollars) Fifteen million, three hundred thousand united states dollars to you, as far as I can be assured that my share will be safe in your care until I complete my service here in Iraq, this is not a stolen money but the gift of my dedicated service.

Some money in various currencies was discovered in barrels at a farmhouse near one of Saddam's old palaces in Tikrit-Iraq during a rescue operation, and it was agreed by staff Sgt David buff and I that some part of this money be shared among both of us before informing anybody about it since both of us saw the money first considering that no military compensation can be of better value for the risk we have taken with our lives in this hell hole.

The above figure was given to me as my share, and to conceal this kind of money became a problem for me, so I carefully packaged and sealed it properly and with the help of a British contact working here and his office enjoy some immunity, I was able to get the package out to a safe location entirely out of trouble spot having told him it is medical photographic laboratory materials belonging to a British/American medical doctor who died in a raid here in Iraq, and before giving up, trusted me to hand over the package to his family in united states and he believed me knowing fully the environment in Iraq.

Now I have decided to use you if you are willing to assist me in this matter to receive the money from the diplomats as the money has been packed as family valuables and it will be delivered to you in America in two days and or any of your current destination in case you are outside the states as it was carefully arranged in US\$100 Bills.

Upon the arrival of the diplomat in your desired destination, he will contact you on your direct phone number for the clearance of the consignment from the homeland security at J.F.K international airport, and or your present destination international airport and thereafter, he will proceed to your home which is the final destination for delivery completion. Therefore, kindly provide me with the following informations for submission to the carrier company as to make waybill delivery which I will collect and send copy to you. (a)Your Full Name: (b) Your Address: (c) Your Telephone Number: (d) Your Fax Number: (e) Your Mobile Number

IO

My late Father deposited one trunk of box with a security company here before his dead and because of situation of political crisis here that led to war going on here in my country, we need some body that I will trust to come in and help me and my brother claim this consignment out from the company for the safety of my property that was deposited under there custody. Please I am contacting you for your assistance, to help me and my brother because we don't have anyone in here to help us and I don't have money to travel from here to any country please I need your assistance to stand by me and my brother and help us to transfer the box to your for future investment. You will contact the security company as Miss Flora Abe foreign partner who want to help me and claim the box that was deposited by late Father MR David Abe from Republic of sierra Leone. 
My late Father did not declared the real content of the box to the security company officials. He only told them that the box is containing family valuables. You are the only person I have sent this message across to. I will like you to keep the secret until this box arrive your country. You have to promise me that you will not betray me and my brother when this box is under your care. I will send the documents and the security company contact to you once you accept to help me and my brother. You have to give me your private phone and fax number to enable me to send the documents to you. The money inside the trunk box is Nine Millions Five Hundred Thousand Dollars (\$9.5 Millions Dollars).

While performing representative acts, the entire corpus is replete with doubtful information, some lacking logicality and common sense. The narratives are filled with assertions that are contradictory, exaggerated and suggestive; some contradict general knowledge and others can simply be seen as outright lies. Notice that all the narratives involve the death of a persona and in most cases with his entire family. Over $80 \%$ of the deaths are accidental, mostly plane crash. The deceased in most cases leaves no relatives or next of kin to claim their wealth. Where some relatives exist, they are devious and unreliable. The writer of BFI for example begins with "For some years now, your funds that is supposed to be transferred into your account as a foreign contractor or next of kin who is entitled to inherit the deceased money has been delayed base on series of unnecessary reason". This kind of beginning certainly leaves the receiver guessing: "what funds, what deceased money..." etc. While he claims that the new Nigerian president has solved all problems involving transfer of the so called funds, he went on to say that "we have settled with the United States Monetary Fund Agent also Europe..." and one wonders what this means and the connection here. This writer talks about "deceased funds" at the beginning of his narrative, surprisingly towards the end, it turns out to be "contractor's funds". One wonders which is which. Is the "beneficiary" also the "contractor"? In IO the "boy" who claims to have a box filled with millions of US dollars has no money to travel to any country. In MT the receiver is to meet a "diplomat" at the JF Kennedy International Airport, while the receiver is in Nigeria. One wonders how possible this is etc. The spurious accounts and processes are all too obvious to common sense.

While stating the 'facts' of the story they are also appealing, praying, and requesting, hence, performing directive acts at the same time. The writers want the receivers to know why they are making the proposals and why they must patronize the business. Examples below are from the data:

'It is therefore upon this discovery that I now decided to make this business proposal to you, so that the money can be release to you as the next of kin or relation to the deceased for safety and subsequent disbursement.' (NKC)

'I want somebody that will use this fund according to the desire of my late husband to help Less privileged people, orphanages, widows and propagating the word of God.' (CD)

'Please I need your assistance to stand by me and my brother and help us to transfer the box to your for future investment.' (IO)

Since it is obvious that the primary intention of the writers of the these proposal is to deceive and defraud, we can conclude with Heyd (2008) that these hoax emails are non cooperative; they overtly violate the cooperative principles proposed by Grice (1975), particularly the maxims of quality ("do not say what you believe to be false"). The writers have proved "that cooperation may be suspended in particular talk exchanges: speakers (or writers) can and do behave highly non-cooperatively" (Heyd 2008: 134). It is necessary to state here that it is only people who desire to get rich quick that can fall for this temptation. However, it is believed that the general economic insecurity and the current global financial crises have driven young people into new and creative ways of committing crime and fraud. 


\subsubsection{Invitation to Business/Offer of Revenue}

Since email communication is essentially bi-directional, it is impossible to assess the receiver's physical reactions, so the writers of these business proposals introduce communicative methods that would serve as buffers to their claims, as a form of reassurance/confidence building. In the data, the writers mostly perform directive and commissive acts of inviting and making offers to the receivers. The receiver is to trust the writer and be convinced that the business is genuine. A few examples are given as follows:

NKC

I agreed that $30 \%$ of this money will be for you as a respect to the provision of a foreign account, $10 \%$ will be set aside for expenses incurred during the business and $60 \%$ would be for me. Thereafter, I will visit your country for disbursement according to the percentage indicated Therefore, to enable the immediate transfer of this fund to you arranged, you must apply first to the bank as relation or next of kin to the deceased customer with a text of application that $i$ will send to you, but before i send to you the text of application form. I will like you to send me the following informations: FULL NAME, NATIONALITY, AGE, and OCCUPATION.

$\mathrm{CD}$

I took this decision because I don't have any child that will inherit this fund, And I don't want in away where this money will be used in an ungodly way. This is why I am taking this decision to hand you over this Fund. I am not afraid of death hence I know where I am going. I want you to always remember me in your daily prayers because of my up coming Cancer Surgery. Write back as soon as possible any delay in your reply will give me room in sourcing another person for this same purpose. Hoping to read from you asap.

\section{FBI}

I want to use this opportunity to make my own profit, if you agree that you will give me $5 \%$ of the total fund so that I will take it upon myself and make sure that you will be among the contractors that will receive their contract funds in the next day. Upon your acceptance reply to this transfer deal. I will do all the underground work here in the CBN to make sure that the funds will be transferred to you through the appointed paying bank.

\section{MT}

Now I have decided to use you if you are willing to assist me in this matter to receive the money from the diplomats as the money has been packed as family valuables and it will be delivered to you in America in two days and or any of your current destination in case you are outside the states as it was carefully arranged in US\$100 Bills... Therefore, kindly provide me with the following informations for submission to the carrier company as to make waybill delivery which I will collect and send copy to you. (a) Your Full Name: (b) Your Address: (c) Your Telephone Number: (d) Your Fax Number: (e) Your Mobile Number

IO

I will send the documents and the security company contact to you once you accept to help me and my brother. You have to give me your private phone and fax number to enable me to send the documents to you. The money inside the trunk box is Nine Millions Five Hundred Thousand Dollars (\$9.5 Millions Dollars)...I will offer you 10\% for the total sum of amount, if you help me and claim this box from the security company. You will also provide investment programme where the money will be invested properly when it arrival your hand safely.

I wait to hear from you.

In almost all the emails in the data, the receiver is urged to "call me immediately", "write back as soon as possible" or "to send the following documents...". The writers rely on their 
supposed identity as bank managers, legal practitioners or as highly successful men of industry to reassure the receivers of their sincerity and good intentions. Some present themselves as religious people or 'born again' and they make promises triggered by statements such as "I have decided to give...", "I agree that $30 \%$ of this money will be for you...", "I will take it upon myself to make sure..." etc. Commissives such as these require that anyone making them should be in position to fulfil them before they can be considered felicitous (Adegbija 1995). However, common knowledge has proved that people who get themselves into online scams eventually lose all their money. This shows that the apparent commissive acts turn out to be mere communicative strategies to sell fraudulent businesses to the prospective victims.

\subsubsection{Request for Confidentiality}

In many of the emails, the writer urges the addressee to keep the business proposal confidential. This advice often comes at the closing of the mails. In some, it is the subject header that reads: "Top Secret". Examples in the data include:

(a) Please be informed that your utmost confidentiality is required.

(b) I will please wish you keep this transaction secret as I am hoping to retire with my share of this money at the end of transaction.

(c) I advice that we should make secrecy and confidentiality as our primary working condition.

(d) Needless to say, UTMOST CONFIDENTIALITY is of vital importance if we are to successfully reap the immense benefits of this transaction.

(e) Please keep this proposal as a top secret and delete if you are not interested.

Ironically the senders of deceptive mails are asking for sincerity, trust and confidence from the addressee. They emphasize the need for trust and strict confidentiality. 'Confidentiality' in this sense is to make the receiver consider the offer as genuine and worth investing in before anyone else knows about it. It is an anxiety booster on the receiver to act quickly. This also implies that the business can proceed without any formal legal procedures or negotiations. However it is quite clear that the impression that the initial demand of the transaction is basically trust and confidentiality is a mere pretence.

\subsubsection{Closing/Sign off}

As noted above, the writers of hoax emails often borrow from established genres of discourse. So they borrow extensively from the normal business discourse because the more businesslike a message appears the more people tend to believe them. About $89 \%$ of the mails end with a formal closing often with the name of the writer as sign off. Table 3 below give the picture of the formal closing and sign off formulas.

\begin{tabular}{|lrr|}
\hline Closing \& Sign off & no. & $\%$ \\
\hline Regards & 10 & 21.0 \\
Yours faithfully & 10 & 20.0 \\
Best regards & 6 & 12.2 \\
Sincerely & 2 & 4.0 \\
Kind regards & 2 & 4.0 \\
With regards & 2 & 4.0 \\
Regards from & 2 & 4.0 \\
Yours sincerely & 1 & 2.0 \\
Thanks & 1 & 2.0 \\
\hline
\end{tabular}




\begin{tabular}{|lrr|}
\hline Thanks and best regards & 1 & 2.0 \\
Best regards and wishes & 1 & 2.0 \\
I await your call, best regards & 1 & 2.0 \\
Have a great day, yours faithfully & 1 & 2.0 \\
Thanking you in advance & 1 & 2.0 \\
Trusting to hear from you immediately & 1 & 2.0 \\
Please keep this proposal a top secret, regards & 1 & 2.0 \\
God bless you & 1 & 2.0 \\
Thanks and remain blessed & 1 & 2.0 \\
Remain blessed in the name of the Lord & 1 & 2.0 \\
Yours in Christ & 1 & 2.0 \\
May God bless you as you write back, yours in Christ & 1 & 2.0 \\
Respectfully submitted & 1 & 2.0 \\
God bless you as you listing to the voice of reasoning, Yours in Christ & 1 & 2.0 \\
God bless you for your anticipated understanding and Cooperation, Best regards & 1 & 2.0 \\
\hline & 49 & 100.0 \\
\hline
\end{tabular}

Table 3: Closing and Sign offs

The study shows that closing remarks and sign offs occur more frequently than the opening formulas. Since hoax emails take after the business style of commercial communication, they necessarily include closing and sign off. Even the emails without greetings end with closings and sign offs and this account for about $94 \%$ of the data with formal/informal closing formulas. Only about $6 \%$ are without closing though with the names of the writers as sign off. The writers expect a reply, so they include their 'names' and contact emails as a matter of necessity. Closing and sign offs generally perform expressive speech acts.

Personal/place names features prominently in the contents of the emails. In particular, personal names are usually found in the address information at the email header, showing the sender and often the receiver. They also form part of the footer information/sign off. By linking the names of very important personalities such as heads of states or their spouses, top government officials and top business people, with their own identities, the writers attempt to provide credibility to their deceptions. In recent times, names of academics and editors are also faked. In FBI sample above, the writer claims to be the personal assistant to Prof. Chukwuma Soludo, former Nigeria's Central Bank Governor and in the MT sample, the author claims that certain huge sum of money was dumped in "Saddam's old palaces in TikritIraq". Other familiar names include "James Koromah" (Sierra Leone), and "Marian Kibaki" (Zimbabwe). Proper names therefore perform discourse roles such as naming the writer of the mail, or as reference to a third person. The third person may be a prospective recipient of certain favours in the message or simply as means of attracting some credibility to the hoax mail. Most of the personal names in the data such as Saliu Kabore, Yi Kwan, Joseph Chau, Rebecca William, Elina Robert etc. are mere inventions.

\section{Conclusion}

This study shows that the various forms of hoax email business proposals are deliberate efforts of certain people to use language in a particular way to deceive others and make quick money from them. The use of language pragmatically gives the hoax mails their influential powers despite their linguistic and stylistic shortcomings. The study reveals that the business proposals perform speech acts such as expressive, representative, commissive and directive acts; the most frequently used being representative as the proposals are structured as narratives. Because the writers hoped to persuade and convince the addressees, they told stories that are unfortunately quite doubtful, some lacking logicality, while some contradict general 
knowledge and are outright lies. The expressive act is used in form of greetings and polite address forms in order to win the interest of the receiver. Greeting forms are used as a tool for creating a comfortable atmosphere for social interaction. Just as most business letters contain formal openings as a form of politeness strategy, the writers of the hoax mails apply them as positive politeness to appeal for social relationship, solidarity and smooth communication. The commissive act is used as a persuasive strategy to make promises that generally appear unrealistic and suspicious to the receiver, while the directive act is used to urge the receiver to act promptly. While Blommaert (2005) concludes that the writers of '419' mails are competent manipulators of technological and infrastructural dimension of globalised communication, though failed to demonstrate sufficient technical skills to construct standard business proposals, the present study shows the discourse/pragmatic strategies available in both the structure and contents of the mails which give them their persuasive strength, their generic/linguistic inadequacies notwistanding.

From Heyd's study of form, function, and genre ecology of email hoaxes, she hypothesized that email hoaxing may actually be passing and may soon be extinct. Her conclusion stems from the study that a genre that began in the mid-nineties as virus warnings has indeed, begun to disappear over the years due to high digital literacy of the present times (Heyd 2008). Another reason for her conclusion may stem from the fact that there is online anti-scam software that can restrict or permanently block spam mails. Ironically however, increase in digital literacy has indeed become the very important reason for the spread of '419' emails in recent times. The opportunity offered by the internet for sending messages while remaining anonymous and the control of advanced internet skills have fully incorporated this branch of CMC into the economies of global communication (Blommaert 2005). While Heyd foresees the extinction of hoax virus warning, we predict an increase in the spread of online deceptions in form of '419' business proposals. As a matter of fact, the global economic downturn may eventually serve as a breeder to many more online scams. It is believed that socio-economic problems result in the multiplicity of crimes and fraudulent practices. Hence, extinction of hoax emails business proposals are not likely in the near future; rather than disappear they are very much likely to develop other complex varieties.

\section{References}

Adegbija, Efurosibina (1995): "'I, Major-General X'. Discourse Tacts in Military Coup Speeches in Nigeria". Text 15/2: 253-270.

Agyekum, Kofi (2008): "The Pragmatics of Akan Greetings". Discourse Studies 10/4: 489512.

Austin, John (1962): How to Do Things with Words. Oxford.

Baron, Naomi S. (1998): "Letters by Phone or Speech by Other Means. The Linguistics of Email". Language \& Communication 18/2: 133-170.

Barron, Anne (2006): "Understanding Spam: A macrotextual analysis". Journal of Pragmatics 38/6: 880-904.

Blommaert, Jan (2005): "Making Millions. English, Indexicality and Fraud". Working Papers in Urban Language \& Literacies 29: 1-24.

Brigham, Martin/Corbett, Martin (1997): "Email, Power and the Constitution of Organizational Reality". New Technology, Work and Employment 12/1: 25-35.

Chiluwa, Innocent (2008c): "Religious Vehicle Stickers in Nigeria. A Discourse of Identity, Faith and Social Vision". Discourse \& Communication 2/4: 371-387.

Collot, Milena/Belmore, Nancy (1996): "Electronic Language: A New Variety of English". In: Herring, Susan C. (ed.): Computer-Mediated Communication. Linguistic, Social and Cross-Cultural Perspective. Philadelphia: 13-28. (= Pragmatics \& Beyond 39). 
Fernback, Jan (2003): "Legends on the Net. An Examination of Computer-mediated Communication as a Locus of Oral Culture". New Media and Society 5/1: 29-45.

Frazer, Bruce (1990): "Perspectives on Politeness". Journal of Pragmatics 14: 219-236.

Garton, Laura/Wellman, Barry (1995): "Social Impacts of Electronic Mail in Organizations. A Review of the Research Literature". Communication Yearbook 18: 434-453.

Grice, Paul (1975): "Logic and Conversations". In: Cole, Peter/Morgan, Jerry L. (eds): Syntax and Semantics. Vol. 3: Speech Acts. New York: 41-58.

Heyd, Theresa (2008): Email Hoaxes. Amsterdam/Philadelphia.

Ide, Sachiko (1989): "Formal Forms and Discernment. Two Neglected Aspects of Linguistic Politeness". Multilingua 8/23: 223-248.

Kibby, Marjorie (2005): "Email Forwardables. Folklore in the Age of the Internet". New Media \& Society 7/6: 770-779.

Lan, Li (2000): "Email. A Challenge to Standard English?" English Today 16/4: 23-29.

Mintz, Anne (2002): Web of Deception. Misinformation on the Internet. Medford.

Orasan, Constantin/Krishnamurthy, Ramesh (2002): "A Corpus-based Investigation of Junk Mails". Proceedings of the $3^{\text {rd }}$ International Conference on Language Resources and Evaluation, May 29-31, Las Palmas, Spain. Available at http://clg.wlv.ac.uk/papers/ orasan-02b.pdf.

Searle, John R. (1969): Speech Acts. Cambridge.

Skovholt, Karianne/Svennevig, Jan (2006): "Email Copies in Workplace Interaction". Journal of Computer-Mediated Communication 12/1. Available at http://jcmc.indiana.edu/vol12/ issue1/skovholt.html.

Yates, Simeon J (1996): "Oral and Written Linguistic Aspects of Computer Conferencing". In: Herring, Susan C. (ed.): Computer-Mediated Communication. Linguistic, Social and Cross-Cultural Perspective. Philadelphia: 29-46. 